\title{
THE RESIDENT AS EDUCATOR: MEDICAL STUDENTS' PERCEPTION OF A ONE-WEEK ONLINE PATHOLOGY ROTATION TAUGHT BY RESIDENTS
}

\author{
Cantu-Corona A*, Lopez-Sotomayor DM, Erana-Rojas IE and Lopez M \\ Tecnologico de Monterrey, Escuela de Medicina y Ciencias de la Salud, Av. Ignacio Morones \\ Prieto 3000, Sertoma, Monterrey 64710, NL, Mexico
}

\begin{abstract}
COVID-19 pandemic forced many changes, including how clinical rotations take place. Reducing face-to-face contact transformed a considerable amount of the activities to distance settings. The residents on the pathology program have a crucial role in the undergraduate medical students' learning process. To recreate the regular face-toface contact where members of this learning community would interact, an online oneweek rotation on oncologic pathology was designed. The purpose of this study was to explore the perception of undergraduate students of the role of residents as educators on the pathology rotation taught by residents. A quantitative approach considered a crosssectional and descriptive design to study the phenomenon. The sample consisted of 55 6thyear medical students from a private school in Mexico where the online rotation was taught by residents from July to December 2020. The instrument consisted of a 27-item survey distributed online. Although participants stated they were satisfied with the teaching competence of the residents (mean 4.54), there seems to be a disagreement that the practical part of the sessions, where microscopy techniques are used, should be taught by them (mean 3.84). Students highlighted that they felt more comfortable and relaxed, as well as more confident in asking questions with residents than they did with medical specialists. The resident-student interaction is an enriching learning opportunity for both. Near peer contact found in the residents' role as educators still needs to be formalized in the curriculum but an initial adaptation done during the pandemic might show its contribution.
\end{abstract}

Keywords: higher education, educational innovation, teaching, medical education, residents, educators' role, pathology

\section{Introduction}

On March 11th, 2020, the World Health Organization (WHO) declared COVID-19 as a pandemic (Cucinotta \& Vanelli, 2020). This unprecedented event forced many activities to change to a virtual environment to try to mitigate the contagion curve and with this saturation of the health systems; medical schools faced a double dilemma. They needed to establish strategies to guarantee the safety of their educational community while continuing their professional training. That is, develop the next generation of physicians, psychologists, nurses, and dentists who could help battle challenges such as the current pandemic. 


\section{Learning Pathology}

Anatomical pathology is a fundamental part of the medical curriculum; students need to understand the different structures in the body and the interactions between organs and their functions. The term "pathology" derives from Greek "pathos" and "logos", meaning "disease" "study of", respectively. It is considered as the missing link that reconciles the basic and clinical sciences blocks within the program. With pathology, students integrate concepts from anatomy, cellular, developmental and molecular biology, physiology, biochemistry, immunology, genetics, microbiology, pharmacology, and public health (Valencia-Mayoral and Ancer-Rodriguez, 2014). The mixture of these complex concepts is actually similar to how professionals need to approach a patient's medical problems to try to reach a diagnosis.

An important contribution to the teaching-learning process in pathology has been the evolution of technologies that allow the use of new teaching techniques. Some innovations have focused on developing multi-view devices to adapt the conventional microscopes for multi-person viewing in real-time. In these adaptations, either a professor can drive the microscope for students to see on different viewing ports the same specimen or one student may drive, while another describes the morphological finding analysis of the specimen and the rest observe. Through the viewing ports, students may record with their smartphones for a later review, the morphological analysis and thinking process encountered. These innovations in teaching pathology facilitate collaboration, communication, and interactions between students (Braun and Kearns, 2008, Sağol et al., 2015, Laohawetwanit, 2020).

However, the definition of a new era for teaching pathology could be attributed to the inclusion of digital technologies where the traditional histological pathology sessions are enhanced by imagining techniques and devices to allow the digitization of the glass slide specimens. The images to be studied are correctly focused pictures of the specimen of interest and students only need to focus on identifying the pathological findings that can approach them to the correct diagnosis. Digitized slides allow multiple viewers to analyze images synchronously or asynchronously; it is a cost-efficient model, as there is no need to purchase expensive multi-headed equipment nor to keep a budget for maintenance. In regards to the use of human resources, digital pathology reduces the need to have the required personnel within a fixed lab schedule. Time efficiency is another advantage of these strategies, in comparison with conventional pathology teaching, as students do not lose time in the technical aspects of using a microscope. To set a clear understanding of the teaching-learning process students may include annotations on captured images of the digitized slides to clarify and improve their communication with the instructor; annotations can be exchanged by email or through a Learning Management System (Saco et al., 2016; Eraña et al., 2016).

In prior work, Eraña et al. (2018) developed a virtual pathology lab experience, where digital pathology was applied. In this implementation, students interacted with digital slides and learned through a structured curriculum to identify microscopic abnormalities, explain the interaction of functional disorders and their causes. The authors reported positive students' feedback regarding class dynamics and the perceived application in their future professional contexts. Similarly, Zelada and Vargas (2016) described a virtual teaching implementation of an integrated curriculum of semiology, clinical pathology, and radiology, whereas as a result of the experience students obtained better grades in the partial and final exam and they valued the experience favorably. 


\section{Learning from residents}

Postgraduate studies in medicine have the particularity of being both a learning space and a working position. Learners participate in academic sessions and traditional seminars to learn the basics of the sciences behind their specialties of choice; meanwhile, they have heavy involvement in direct patient care. These responsibilities often collide in a learning space where the practice is required to achieve mastery of skills. In their available time, residents which are students enrolled in postgraduate clinical studies, have also the responsibility of supervising junior learners in their clinical services. For example, they supervise and care for undergraduate students in hospitals. It has been estimated that residents may spend up to $25 \%$ of their time supervising, instructing, and evaluating students or junior colleagues; in undergraduate programs, approximately $30 \%$ of the learning interactions come from residents (Snell, 2011).

These interactions between learners in different stages of development focusing on the senior student helping the junior learner is called near-peer teaching (Cambrón-Carmona et al., 2016). This model where everyone has a responsibility to care for a learner is part of the professional culture in medical schools (Lopez, Olivares \& Heredia, 2020). The effectiveness and advantages of these interactions have been described in many studies, such as apparent easier understanding between peers if compared with the traditional teacher-student interaction. Some authors have emphasized its contribution to teaching hands-on skills that require repetition, practice, and feedback for improvement (Rosenberg, Nanos, and Newcomer, 2016). Undergraduate students' appreciation of their interaction with residents has been positive. For example, the perception of the feedback that they receive from residents in services such as Internal Medicine, Neurology, Pediatrics and Surgery, was rated comparable to the one given by faculty. One factor that contributes to these results is that residents generally spend more time directly interacting with medical students, the residents can monitor and assess the development that the students experience in their settings. Generally, facultystudent interaction tends to be more limited (Rubin and Rarey, 2004). Another factor is that senior residents are like seeing yourself in a mirror experience, or at least the possibility of your future self.

In Mexico, as in other countries, senior residents have greater responsibility regarding patient care, therefore they have become the supervisors of personnel in different levels of professional development, they mentor medical students, nurses, and junior residents (Sánchez-Mendiola et al., 2010). However, they receive little to no training to do so. Few universities include in the residency curriculum courses to equip them with the educational bases for these interactions (Lavjay Butani $e t$ al., 2013). It is important that residents receive training and that their roles as teachers are formalized (Méndez-López et al., 2013).

As with other residents, it is expected that pathology residents have a role in the training of medical students (Allen, 2013). However, this topic has scarcely been studied compared to that of specialists' participation in the training of medical students. Particularly in Pathology, interactions of students and residents are poorly described, while these are more often seen between residents from other specialties and undergraduate students. Probably because, during the clinical years in most medical programs, the pathology clerkship is not mandatory and just a few students with this particular interest, get to know residents from this specialty (Ramachandran, 2013; Samueli et al., 2020). 


\section{Learning amid the pandemic}

To allow the medical training to continue despite the health emergency that COVID has represented, several programs implemented distance learning models. For example, a remote surgical pathology elective was implemented to subside the medical students' need for virtual learning as they were not allowed in hospitals due to the pandemic (Samueli et al., 2020). Some models have relied on virtual classrooms, webinars, and open online courses to complement learning (Kaup et al., 2020). Others relied on a mix of live and pre-recorded lectures and written discussion forums to maximize engagement (Gottlieb et al., 2020).

In the institution where the study was conducted, medical clerkships were canceled from mid-March 2020 and the activities remained completely virtual for 16 weeks. Thereafter, students continued their clinical activities in a semi-presential mode, leaving activities with the possibility of being virtual to this modality. To continue training medical students in pathology, a semi-face-to-face rotation was prepared in the topic of oncopathology. Oncopathology refers to the branch of science that studies the pathology of cancer, including malignant and non-malignant tumours, metastasis, tumorigenesis, and carcinogenesis.

The coordination and most of the interaction was with the first and second-year residents of the Pathology program. It consisted of a one-week semi face-to-face rotation in which 2 to 4 undergraduate students were enrolled each week. Their activities included: an individual face-to-face assistance to the pathology lab, where for 2 hours each student observed and assisted in the gross examination of specimens; 4 virtual microscopy small group sessions with first and second-year pathology residents, where they studied the microscopic findings of oncological cases; 4 virtual academic theoretical sessions, where two sessions were taught by residents and supervised by pathologists on topics related to histology and general and systemic pathology, and two sessions where each student presented a complete oncological case seen during the microscopy sessions earlier on the week.

The microscopy sessions were performed through a camera connected to the microscope, with the image projected through the ZEN program and sharing the screen with the students through the Zoom platform. Previous to this rotation, both residents had already taken a course on medical education of 50 hours duration which is part of their curriculum.

The purpose of this study was to explore the perception of undergraduate students of the role of residents as educators on the pathology rotation taught by residents.

\section{Methods}

A quantitative and cross-sectional study was realized to perform a descriptive analysis of the medical students' perceptions. The studied population included 55 students of the sixth year of medicine in a private university in northern Mexico, who were enrolled in a one-week oncopathology course. The study covered two consecutive quarters July-September 2020 and October-December 2020, with 21 and 34 students, respectively. The students voluntarily and anonymously answered the survey at the end of their rotation. 
The information was collected through a survey in Spanish; items have been translated to be reported in this paper. The survey included demographic data of sex and age, and 27 items focused on the perception that students had while being taught by residents instead of specialists during their interactions. The instrument emerges from the research performed by Zabar et al. (2004), Nelson et al. (2013) and Cambrón-Carmona et al. (2016). A Likert scale from 1 to 5 was used, where 1 means total disagreement and 5 total agreement. The survey was sent through a Google Forms application.

For the statistical analysis of the data, the Minitab version 19.2020.2 software package was used to process the information. For each item, the mean, standard deviation and confidence interval were calculated.

\section{Results}

Responses were received from 50 students (91\%), 26 women (52\%) and 24 men (48\%) between 22 and 26 years old $($ mean $=23.5$, standard deviation $=0.8)$. According to the results, medical students considered they did learn in the sessions taught by the residents (mean $=4.66)$ and that the subject content was not limited by the online format (mean $=4.18)$. These results are presented in Table 1 . During these sessions, compared to those taught by specialists: the students felt more comfortable and relaxed (mean $=4.48$ ), more confident to ask questions (mean $=4.46$ ), to participate in a practical activity (mean $=4.38$ ) and understood better the content with the language and expressions used by residents $($ mean $=4.38)$.

Table 1: Perception of students about residents as teachers in the clinical oncopathology course

\begin{tabular}{llll}
\hline Item & Mean & $\begin{array}{c}\text { Standard } \\
\text { deviation }\end{array}$ & CI 95\% \\
\hline I learned in the microscopy sessions delivered by residents & 4.66 & 0.63 & $(4.48,4.84)$ \\
\hline $\begin{array}{l}\text { Having been taught this session by residents, I felt more } \\
\text { comfortable and relaxed compared with the sessions delivered } \\
\text { by specialized doctors }\end{array}$ & 4.48 & 0.74 & $(4.27,4.69)$ \\
\hline $\begin{array}{l}\text { Having been taught this session by residents, I felt more } \\
\text { confident to ask questions compared with the sessions } \\
\text { delivered by specialized doctors }\end{array}$ & 4.46 & 0.86 & $(4.22,4.70)$ \\
\hline $\begin{array}{l}\text { Having been taught this session by residents, I was more } \\
\text { confident to take part in the practical activities, compared } \\
\text { with the sessions delivered by specialized doctors }\end{array}$ & 4.38 & 0.85 & $(4.14,4.62)$ \\
\hline $\begin{array}{l}\text { The language and the explanations employed by residents } \\
\text { made the contents more comprehensible, compared with the } \\
\text { sessions delivered by specialized doctors }\end{array}$ & 4.38 & 0.78 & $(4.16,4.60)$ \\
\hline $\begin{array}{l}\text { The information was transmitted clearly by the residents } \\
\text { I agree with being evaluated by residents. }\end{array}$ & 4.6 & 0.64 & $(4.42,4.78)$ \\
\hline $\begin{array}{l}\text { I prefer for the microscopy sessions to be given by residents } \\
\text { instead of specialized doctors in the subject }\end{array}$ & 3.84 & 1.09 & $(4.46,4.87)$ \\
\hline $\begin{array}{l}\text { How do you evaluate the overall teaching performance of } \\
\text { residents? }\end{array}$ & 4.64 & 0.60 & $(3.53,4.15)$ \\
\hline $\begin{array}{l}\text { The content of this course is not limited because of the online } \\
\text { format }\end{array}$ & 4.18 & 1.17 & $(4.47,4.81)$ \\
\hline
\end{tabular}


According to the section of "how residents..." students believe residents created a non-threatening learning environment (mean $=4.86$ ), had a solid understanding of the course content (mean $=4.7$ ), provided useful feedback (mean $=4.6$ ), inspired them to learn $($ mean $=4.54)$, they were role models of professionalism (mean $=4.76$ ), they were as mentors (mean $=4.64)$, they inspired them to teach in the future (mean $=4.3$ ), their communication was nonjudgmental, respectful and had an empathic attitude (mean $=4.9$ ) and showed appropriate non-verbal behavior (mean $=4.84$ ). Regarding the assessment, the students considered that the residents assessed skills $($ mean $=4.54)$ and helped in closing the gaps in knowledge (mean $=4.56)$. These results are seen in Table 2 .

Table 2: Perception of direct residents contribution

\begin{tabular}{llll}
\hline Item & Mean & $\begin{array}{l}\text { Standard } \\
\text { deviation }\end{array}$ & CI 95\% \\
\hline Created a non-threatening learning environment & 4.86 & 0.45 & $(4.73,4.99)$ \\
\hline Had a sound understanding of course content & 4.70 & 0.54 & $(4.55,4.85)$ \\
\hline Provided helpful feedback & 4.60 & 0.70 & $(4.40,4.80)$ \\
\hline Inspired me to learn & 4.54 & 0.71 & $(4.34,4.74)$ \\
\hline Were role models for professionalism & 4.76 & 0.52 & $(4.61,4.91)$ \\
\hline Provided a mentorship role & 4.64 & 0.66 & $(4.45,4.83)$ \\
\hline Inspired me to teach in the future & 4.30 & 0.97 & $(4.02,4.58)$ \\
\hline Communication was nonjudgmental, respectful and with an & 4.90 & 0.30 & $(4.81,4.99)$ \\
empathic attitude & & & $(4.66,5.0)$ \\
\hline Exhibited appropriate nonverbal behavior & 4.84 & 0.62 & $(4.34,4.78)$ \\
\hline Assessed knowledge gaps & 4.56 & 0.79 & $(4.30,4.79)$ \\
\hline Assessed skills & 4.54 & 0.86 & $(4.4,4.83)$ \\
\hline Asked the learner to commit to a diagnosis or plan & 4.62 & 0.73 & $(4.47,4.85)$ \\
\hline Probed to foster the thinking process & 4.66 & 0.66 & $(4.61,4.95)$ \\
\hline Provided knowledge and taught skills & 4.78 & 0.58 & $(4.41,4.83)$ \\
\hline Provided feedback on specific subjects & 4.62 & 0.73 & $(4.47,4.85)$ \\
\hline Assessed students' understanding of what was taught & 4.66 & 0.66 & $(4.77,4.99)$ \\
\hline Were open to students questions & 4.88 & 0.39 & \\
\hline
\end{tabular}

However, although they were satisfied with the teaching competence of the residents, even considering them among their best teachers (mean $=4.54)$, they did not completely agree that the microscopy sessions were taught by them instead of by the specialists (mean $=3.84$ ). There were no statistically significant differences in the answers considering gender as a factor ( $p>0.05)$.

\section{Discussion}

This research shows that the students highly value the sessions taught by the residents. They perceived that they learned, in a relaxed way, felt confident to ask questions, and believed that the information was transmitted correctly by the residents. These findings are consistent with the results of the study conducted by Cambrón-Cardona et al., which found that pathology histology sessions, which are hands-on experiences could be taught by senior learners to junior trainees. However, in our study students seem to prefer that the more technical and specialized sessions are taught by specialists. 
Students perceived that residents have appropriate non-verbal behavior and communicate without prejudice, with a respectful and supportive attitude. Regarding their instructional and assessment ability, students consider that residents assess skills and gaps in knowledge, support the thinking process, give information and teach skills, provide feedback, corroborate student understanding, are open to questions from students, and they ask the students to commit to the diagnosis and plan.

Although the residents participating as teachers in this rotation had little experience as professors, medical students said they were satisfied with the overall performance of residents, and thought the online format of the rotation wasn't a limiting factor to the learning process.

Samueli et al. (2020) reported a similar experience that was well accepted by their students of an online surgical pathology course implemented in Israel. However, it only had 45 minutes of online interaction between the instructor and the learners and the rest of the experience was independentstudy. While our study had a 10-hour long interaction between students and residents contributing to the enriching learning environment and students' acceptability.

The limitations of this study relate to the small sample of participants that are part of the Pathology program, and due to the implementation being within a single institution. The Pathology rotation is hard to compare as it is not commonly offered in other universities or hospitals, and it is the first time it is mandatory in our institution. But future implementations might integrate other residency programs to see if these findings could be generalized. Another important factor to explore is that this assessment was a one-sided evaluation of the interaction of pathology residents with students, a future implementation could analyze whether the academic and mentoring benefits were perceived as well by the residents.

\section{Conclusion}

The day-to-day life of the medical profession includes the participation of intra-and interdisciplinary groups of professionals with different ages and grades of experience. Although in the first years of the curriculum is delivered by professors in the classroom setting, once in the clinical stage students interact with medical specialists, general physicians, nurses, residents, and fellow students that share the context. These interactions are vital for the learning process and must be considered as part of the formal curriculum offered in future educational plans.

Residents created a non-threatening environment, had a sound understanding of the course content, provided helpful feedback, and provided mentoring. These models could be adapted to other disciples where learners interact with students in more advanced stages. Besides the academic benefits of nearpeer relationships, the interactions with residents allowed students to their future self and became an inspiration to keep working for their professional future.

\section{Acknowledgements}

The authors would like to acknowledge the financial support of Writing Lab, Institute for the Future of Education, Tecnologico de Monterrey, Mexico. 


\section{References}

Allen, T. C. (2013). In Reply. Archives of Pathology \& Laboratory Medicine, 137(10), 1325-1325. https://doi.org/10.5858/arpa.2013-0321-LE

Braun, M. W., \& Kearns, K. D. (2008). Improved learning efficiency and increased student collaboration through use of virtual microscopy in the teaching of human pathology. Anatomical Sciences Education, 1(6), 240-246. https://doi.org/10.1002/ase.53

Cambrón-Carmona, M.A., Tallón de Lara, C. N., Ruz Caracuel, I., Leiva Cepas, F., González, R. G., Zurita Lozano, S., Cámara Pérez, J., Casado Ruiz, J., \& Peña, J. (2016). Near-peer Teaching in Histology Laboratory. International Journal of Medical Students, 4(1), 14-18. DOI:https://doi.org/10.5195/ijms.2016.144.

Cucinotta, D., \& Vanelli, M. (2020). WHO Declares COVID-19 a Pandemic. Acta Bio Medica Atenei Parmensis, 91(1), 157-160. https://doi.org/10.23750/abm.v91i1.9397

Eraña Rojas, I.E., Barbosa Quintana, A., Pérez Saucedo, J.E., Segura-Azuara, N.A., \& Lopez, M. (2018). The virtual pathology lab experience. International Journal on Interactive Design and Manufacturing, 12(4), 1299-1308. https://doi.org/10.1016/j.edumed.2016.08.004v

Eraña Rojas, I. E., Pérez Saucedo, J. E., Barbosa Quintana, Á., Segura-Azuara, N. de los Á., \& López Cabrera, M. V. (2016). Una nueva forma de aprender patología: laboratorio virtual de patología. Educación Médica, 18(4), 249-253. http://dx.doi.org/10.1016/j.edumed.2016.08.004

Gottlieb, M., Landry, A., Egan, D.J., Shappell, E., Bailitz, J., Horowitz, R., \& Fix, M. (2020). Rethinking residency conferences in the Era of COVID-19. AEM Education and Training, 4(3), 313317. https://doi.org/10.1002/aet2.10449

Kaup, S., Jain, R., Shivalli, S., Pandey, S., \& Kaup, S. (2020). Sustaining academics during COVID19 pandemic: The role of online teaching-learning. Indian J Ophthalmol, 68, 1220-1221 https://doi.org/10.4103/ijo.IJO_1241_20

Laohawetwanit, T. (2020) The use of virtual pathology in teaching medical students: first experience of a medical school in Thailand. MedEdPublish, 9(1), 116, https://doi.org/10.15694/mep.2020.000116.1

Lavjay Butani, Debora A. Paterniti, Daniel J. Tancredi \& Su-Ting T. Li (2013) Attributes of residents as teachers and role models - A mixed methods study of stakeholders, Medical Teacher, 35(4), e1052-e1059, https://doi.org/10.3109/0142159X.2012.733457

Lopez, M., Olivares, S., \& Heredia, Y. (2020). Professional culture in medical schools: a medical educator interpretation. Medical Science Educator, 30(1), 281-286. https://doi.org/10.1007/s40670019-00896-x

Méndez-López, J.F., Mendoza-Espinosa, H., Torruco-García, U., \& Sánchez-Mendiola, M. (2013). El médico residente como educador. Investigación En Educación Médica, 2(7), 154-161. https://doi.org/10.1016/S2007-5057(13)72705-4

Nelson, A. J., Nelson, S. V., Linn, A. M. J., Raw, L. E., Kildea, H. B., \& Tonkin, A. L. (2013). Tomorrow's educators ... today? Implementing near-peer teaching for medical students. Medical Teacher, 35(2), 156-159. https://doi.org/10.3109/0142159X.2012.737961

Ramachandran, R. (2013). Role of Residents in Medical Student Teaching. Archives of Pathology \& Laboratory Medicine, 137(10), 1325-1325. https://doi.org/10.5858/arpa.2013-0228-LE

Rosenberg, C.J., Nanos, K.N., \& Newcomer, K.L. (2016). The "Near-Peer" Approach to Teaching Muscoloskeletal Physical Examination Skills Benefits Residents and Medical Students. $P M \& R, 9(3)$, 251-257. https://10.1016/j.pmrj.2016.06.004

Rubin, D.J., \& Rarey, K. E. (2004). Resident and Faculty Feedback: The Student's Perspective. In The Medicine Forum, 6(1), 18. https://doi.org/10.29046/TMF.006.1.004 
Saco, A., Bombi, J. A., Garcia, A., Ramírez, J., \& Ordi, J. (2016). Current Status of Whole-Slide Imaging in Education. Pathobiology, 83(2-3), 79-88. https://doi.org/10.1159/000442391

Sağol, Ö., Yörükoğlu, K., Lebe, B., Durak, M.G., Ulukuş, Ç., Tuna, B., Musal, B., Canda, T., \& Özer, E. (2015). Transition to virtual microscopy in medical undergraduate pathology education: first experience of turkey in dokuz eylül university hospital. Turkish Journal of Pathology. https://doi.org/10.5146/tjpath.2015.01329

Samueli, B., Sror, N., Jotkowitz, A., \& Taragin, B. (2020). Remote pathology education during the COVID-19 era: Crisis converted to opportunity. Annals of Diagnostic Pathology, 151612. https://doi.org/10.1016/j.anndiagpath.2020.151612

Sánchez-Mendiola, M., Graue-Wiechers, E.L., Ruiz-Pérez, L.C., García-Durán, R., \& DuranteMontiel, I.. (2010) The resident-as-teacher educational challenge: a needs assessment survey at the National Autonomous University of Mexico Faculty of Medicine. BMC Med Educ 10, 17. https://doi.org/10.1186/1472-6920-10-17

Snell, L. (2011). The Resident-as-Teacher: It's More Than Just About Student Learning. Journal of Graduate Medical Education, 3(3), 440-441. https://doi.org/10.4300/JGME-D-11-00148.1

Valencia Mayoral, P. F., \& Ancer Rodríguez, J. (2014). Patología. España: McGraw-Hill Interamericana de España S.L.

Zabar, S., Hanley, K., Stevens, D. L., Kalet, A., Schwartz, M. D., Pearlman, E., Brenner, J., Kachur, E.K., \& Lipkin, M. (2004) Measuring the competence of residents as teachers. Journal of General Internal Medicine, 19(5), 530-533. https://doi.org/10.1111/j.1525-1497.2004.30219.x

Zelada Vargas, J., \& Vargas Murillo, G. (2016). La enseñanza virtual en la facultad de medicinaUniversidad Mayor de San Andrés una primera experiencia en el pregrado. Cuadernos Hospital de Clínicas, $\quad 57(2), \quad 70-78 . \quad$ http://www.scielo.org.bo/scielo.php?script=sci_arttext\&pid=S1652$67762016000200012 \& \operatorname{lng}=\mathrm{es} \& n r m=\mathrm{iso}>$ 